\title{
A nuclear localization for Avr2 from Fusarium oxysporum is required to activate the tomato resistance protein I-2
}

\author{
Lisong Ma ${ }^{\dagger}$, Ben J. C. Cornelissen and Frank L. W. Takken* \\ Molecular Plant Pathology, Swammerdam Institute for Life Sciences, University of Amsterdam, Amsterdam, Netherlands
}

Edited by:

Susana Rivas, Centre National de la

Recherche Scientifique, France

Reviewed by:

Peter Dodds, Commonwealth

Scientific and Industrial Research

Organisation, Australia

Sebastian Schornack, University of

Cambridge, UK

*Correspondence:

Frank L. W. Takken, Molecular Plant Pathology, Swammerdam Institute

for Life Sciences, University of

Amsterdam, Science Park 904, 1098

XH Amsterdam, Netherlands.

e-mail:f.l.w.takken@uva.nl

${ }^{\dagger}$ Present address:

Lisong Ma, Saskatoon Research

Centre, Agriculture and Agri-Food

Canada, Saskatoon, Canada.

\begin{abstract}
Plant pathogens secrete effector proteins to promote host colonization. During infection of tomato xylem vessels, Fusarium oxysporum f. sp. lycopersici (Fol) secretes the Avr2 effector protein. Besides being a virulence factor, Avr2 is recognized intracellularly by the tomato I-2 resistance protein, resulting in the induction of host defenses. Here, we show that AVR2 is highly expressed in root- and xylem-colonizing hyphae three days post inoculation of roots. Co-expression of I-2 with AVR2 deletion constructs using agroinfiltration in Nicotiana benthamiana leaves revealed that, except for the $\mathrm{N}$-terminal 17 amino acids, the entire AVR2 protein is required to trigger 1-2-mediated cell death. The truncated Avr2 variants are still able to form homo-dimers, showing that the central region of Avr2 is required for dimerization. Simultaneous production of I-2 and Avr2 chimeras carrying various subcellular localization signals in $N$. benthamiana leaves revealed that a nuclear localization of Avr2 is required to trigger 1-2-dependent cell death. Nuclear exclusion of Avr2 prevented its activation of I-2, suggesting that Avr2 is recognized by $1-2$ in the nucleus.
\end{abstract}

Keywords: disease resistance, effector, Avr2, Fusarium oxysporum, tomato, I-2

\section{INTRODUCTION}

Many plant pathogens employ small, secreted proteins called effectors, to facilitate infection and to establish disease (Ellis et al., 2009; Tyler, 2009). Effectors interfere with biological processes of the host to the benefit of the pathogen (Kamoun, 2006; Alfano, 2009). To counteract pathogens, plants evolved resistance (R) proteins to perceive the presence or actions of these effectors (Chisholm et al., 2006; Maekawa et al., 2011). Although some R proteins are cell-surface receptors, most of them are cytosolic proteins of the nucleotide-binding leucinerich repeat (NLR) type. Effector perception leads to activation of "effector-triggered immunity" (ETI), a response that is typically associated with programmed cell death of the infected cells. The induced resistance responses restrict outgrowth of the pathogen from the infection site (Spoel and Dong, 2012).

Many bacterial pathogens, such as Pseudomonas syringae, employ a type III secretion system to directly deliver effectors into the cytosol of plant cells (Shames and Finlay, 2012). Concomitantly, most $R$ genes controlling bacterial pathogens encode NLR immune receptors with a predicted cytosolic location. Plant pathogenic fungi and oomycetes lack a type III secretion system and they secrete their effectors directly into intercellular spaces such as the apoplast or the xylem sap. Although some resistance genes controlling pathogenic fungi encode extracellular immune receptors, such as the $\mathrm{Cf}$ and Ve proteins controlling, respectively, Cladosporium fulvum and Verticillium dahliae (Thomma et al., 2011), most encode intracellular receptors (Dodds and Rathjen, 2010). Resistance to haustorium-forming pathogens is typically conferred by cytosolic receptors (Maekawa et al., 2011). The effectors are secreted into the periplasmic space surrounding the haustorium, from which a subset is taken up by the host cell, allowing intracellular perception (Whisson et al., 2007; Dou et al., 2008; Rafiqi et al., 2010; Schornack et al., 2010; De Jonge et al., 2011). The conserved RxLR motif found in many oomycete effectors is likely involved in the uptake process, as mutations in this motif abolish uptake (Grouffaud et al., 2008). Resistance to xylem-colonizing fungal pathogens that do not form haustoria can also be mediated by cytosolic NLR resistance genes, suggesting the uptake of the corresponding effector from the xylem sap by the host cells. The mechanism by which these fungal effectors enter the host cell, and the subcellular localization where they are perceived by the host immune receptor, are as yet unknown.

The interaction between tomato and the xylem-colonizing fungus Fusarium oxysporum f. sp. lycopersici (Fol) has emerged as a model system to study NLR-mediated recognition of xylem secreted effectors (Takken and Rep, 2010). Fol is a soil born pathogen that causes vascular wilt disease by colonizing the xylem vessels of roots and stems (Michielse and Rep, 2009). Resistance to $\mathrm{Fol}$ in tomato is conferred by so-called "immunity" or " $I$ " genes, and three of these genes have been introgressed from wild Solanum relatives into commercial varieties: $I$ (or $I-1$ ),$I-2$, and $I-3 . I-2$ has been cloned and encodes a classical NLR protein that mediates resistance upon recognition of the Avr2 effector protein from Fol (Simons et al., 1998; Houterman et al., 2009). I-2 promoter-reporter studies revealed that the gene is specifically expressed in the parenchyma cells adjacent to the xylem vessels, but the subcellular localization of I-2 is unknown (Mes et al., 2000). Typically, ETI induces a 
programmed cell death response. However, I-2-mediated resistance seems to be distinct, as Fol recognition triggers specific responses in the parenchymal cells, which include accumulation of phenolics, callose deposition, and formation tyloses (outgrowth of xylem contact cells) and gels in the infected vessels, but not cell death (Beckman, 2000; Takken and Rep, 2010).

Xylem sap proteomics of Fol infected tomato resulted in identification of the Fol Avr2 protein. The AVR2 gene encodes a $15.7 \mathrm{kDa}$ mature protein (after cleavage of the N-terminal signal peptide), without discernable sequence similarity to other proteins (Houterman et al., 2009). Avr2 is not only an avirulence determinant of $I-2$, it is also a virulence factor required for full virulence of the fungus on susceptible plants. Race 3 Fol strains that can overcome $I-2$ carry amino acid substitutions in Avr2 that prevent its recognition by I- 2 while retaining its virulence function (Houterman et al., 2009). Whereas I-2-mediated resistance typically does not involve a cell death response, such as response is induced upon co-expression of AVR2 and $I-2$ in Nicotiana benthamiana using agroinfiltration or upon Potato Virus X-mediated expression of AVR2 in I-2 tomato. The strongest cell death response was found upon expression of a truncated $A V R 2$ variant that is not secreted by the transformed host cells (Houterman et al., 2009). This potentiated response implies intracellular recognition of Avr2 by I-2 and suggests that during natural infection the effector is taken up from the xylem sap by the adjacent plant cells (Houterman et al., 2009).

To determine where in the plant Avr2 is being produced by the fungus, allowing its perception by I-2, we studied the in planta expression of AVR2 during infection. Since Avr2 is perceived intracellularly by I-2, we also examined its subcellular localization and determined the subcellular localization where Avr2 activates I-2. Finally, Avr2 deletion studies were performed to identify the minimal region that is required for dimerization and I-2 activation.

\section{MATERIALS AND METHODS \\ GENERATION OF TRANSGENIC Fol STRAINS}

Homologous recombination was used to replace the AVR2 gene with a cassette containing the gene of interest and a hygromycin resistance gene. To generate the AVR2-promoterRFP construct, the terminator of $A V R 2$ gene was PCR amplified with primer combination FP2708/FP2663 listed in Table A1 using Fol007 genomic DNA as template. The resulting amplicon was cloned into the KpnI site of pRW2h: $\triangle A V R 2$. In this vector the hygromycin resistance gene cassette is flanked by 1266 bp and 717 bp of sequences upstream and downstream of the AVR2 ORF (Houterman et al., 2009). The correct orientation of the AVR2 terminator was confirmed by PCR using primer set FP1074/FP2663. The pRW2h: $\triangle A V R 2-\mathrm{T}$ vector was generated. RFP was amplified from the pGWB454 plasmid DNA using primer set FP2706/FP2707 listed in Table A1 (Nakagawa et al., 2007). The obtained fragments were digested with SpeI, gel purified, and ligated into a SpeI digested pRW2h: $\triangle A V R 2-\mathrm{T}$ vector containing the $A V R 2$ terminator. The orientation of RFP constructs was confirmed by PCR with primer set FP1074/FP2707. The obtained plasmid pRW2h:pAVR2:RFP was transformed into Agrobacterium tumefaciens EHA105 and used for subsequent A. tumefaciens-mediated Fol transformation according to Rep et al. (2004). Fol transformants capable of growing on $100 \mu \mathrm{g} \mathrm{mL}^{-1}$ hygromycin (Duchefa) were checked by PCR for the absence of the AVR2 gene using primer pair FP1074/FP965. Presence of the right and left borders of these constructs was confirmed with primers annealing just outside the flanking sequences, these were FP745/FP1075 (right border) and FP659/FP1166 (left border), respectively. Out of the 150 hygromycin resistant transformants one genuine AVR2 replacement mutant was identified based on the absence of AVR2 and the presence of Monomeric red fluorescent protein (mRFP) and the hygromycin cassette in the AVR2 locus (data not shown).

\section{VECTOR CONSTRUCTION}

For localization studies, the pENTR207: $\triangle s p A V R 2$ or pENTR207:AVR2 plasmid, described previously (Houterman et al., 2009), was used to recombine AVR2 or $\triangle s p A V R 2$ into binary vector pGWB454 and pGWB451 (Nakagawa et al., 2007) according to the Gateway protocol for LR recombination reaction (Invitrogen). In the pGWB454 constructs Avr2 is fused to an RFP tag present in the vector. In the construct pGWB451: $\triangle A V R 2$ Avr2 is fused to a GFP tag present in the vector. To construct NLS- $\triangle$ spAVR2:GFP, a nuclear localization signal (NLS) was introduced into forward primer FP2959 and the fragment was amplified together with reverse primer FP2222 from the pGWB451: $\triangle A V R 2$ plasmid. To construct $\triangle s p A V R 2-N E S: G F P$, part of the nuclear export signal (NES) was introduced into the reverse primer FP3483 and the fragment was amplified together with forward primer FP2525. The fragment obtained with this primer set was used as template for a second round of PCR using primer set FP2525/FP3482. To create CBL- $s p A V R 2-N E S: G F P$, first part of the myristoylation signal (CBL) (Batistic et al., 2008) was introduced into forward primer FP3479 and part of the NES was introduced into the reverse primer FP3483. The fragment obtained with this primer set was used as template for a second round of PCR using primer set FP3478/FP3482. The resulted fragment contained the complete CBL coding sequences in the N-terminus and a NES coding sequence in the C-terminus of AVR2. The fragment harboring the mutated CBL and NES coding sequences was generated using the same strategy but by using primer sets FP3481/FP3485 and FP3480/FP3484, respectively. Finally the four amplicons were digested with $\mathrm{XbaI}$ and SacI, and ligated into pGWB451 digested with the same enzymes.

Three primer combinations: FP2684/FP1751, FP2699/FP1751, and FP1749/FP2685 were used to amplify truncated AVR2 fragments from CTAPi: $\triangle s p A V R 2$. Subsequently, gateway attB linkers were added via PCR using primers FP872 and FP873. The obtained PCR products were introduced into entry clone pDONR207 (Invitrogen, http://www.invitrogen.com/) using the Gateway protocol described by the manufacturer (Invitrogen). The hence obtained pENTR207:: $\triangle s p A V R 2-\triangle 37$ (N-terminal deletion-1), pENTR207:: $\triangle s p A V R 2-\triangle 40$, and pENTR207:: $\triangle s p A V R 2-C T \Delta 11$ (C-terminal deletion) plasmids were recombined into the binary vector CTAPi (Rohila et al., 
2004) using the Gateway protocol (Invitrogen). The resulting plasmids, CTAPi:: $\triangle s p A V R 2-\triangle 37$, CTAPi:: $\triangle s p A V R 2-\triangle 40$, and CTAPi:: $\triangle s p A V R 2-C T \Delta 11$, were used for agroinfiltration as described below.

To generate the constructs used for yeast-two hybrid experiments, the AVR2 ORF, lacking the sequence encoding the signal peptide, was amplified using primer FP1873 and FP1874. As template the AVR2 gene in CTAPi was used (Houterman et al., 2009). The obtained product, carrying NcoI and EcoRI restriction sites, was cloned into the pAS2-1 and pACT-2 (Clontech) vectors digested with the same restriction enzymes.

For co-immunoprecipication experiments binary vectors containing Avr2 were created. $\mathrm{XbaI}$ and $\mathrm{BamHI}$ restriction sites flanking the $\triangle \mathrm{sp} A V R 2$ coding sequence were introduced by PCR with primers FP2525 and FP2274 using CTAPi:: $\triangle \mathrm{sp} A V R 2$ as template (Houterman et al., 2009). The obtained product was sub-cloned into the vector SLDB3104 (Tameling et al., 2010) between the XbaI and BamHI restriction sites to generate SLDB3104:: $\triangle \mathrm{sp} A V R 2$. In the resulting plasmid Avr2 is fused to a C-terminal hemagglutinin (HA) and streptavidin-binding peptide (SBP) tag. All PCR primers were purchased from MWG (http://www.mwg-biotech.com), and sequences of all plasmids were confirmed by sequence analysis.

\section{PROTEIN EXTRACTION AND IMMUNOBLOTTING}

Infiltrated $N$. benthamiana leaves were harvested and pooled $24 \mathrm{~h}$ after agroinfiltration, and snap-frozen in liquid nitrogen. After grinding the tissue with a mortar and pestle, it was allowed to thaw in $2 \mathrm{ml}$ protein extraction buffer per gram of tissue [ $25 \mathrm{~mm}$ Tris $\mathrm{pH} 8,1 \mathrm{~mm}$ EDTA, $150 \mathrm{~mm} \mathrm{NaCl}, 5 \mathrm{~mm}$ DTT, $0.1 \%$ NP40, $1 \times$ Roche complete protease inhibitor cocktail (http://www. roche.com) and 2\% PVPP]. Extracts were centrifuged at $12000 \mathrm{~g}$, $4^{\circ} \mathrm{C}$ for $10 \mathrm{~min}$, and the supernatant was passed over four layers of Miracloth (http://www.calbiochem.com/miracloth) to obtain a total protein lysate. $40 \mu \mathrm{L}$ samples were mixed with Laemmli sample buffer, and equal amounts of total protein were run on $13 \%$ SDS-PAGE gels and blotted on PVDF membranes using semi-dry blotting. Skimmed milk powder (5\%) was used as a blocking agent. A 1:3000 dilution of anti-GFP antibody (VXA6455, Invitrogen), or 1:8000 dilution of anti-tandem affinity purification (TAP) tag antibody (PAP, P1291, Sigma P1291) linked to horseradish peroxidase were used. The secondary antibody goatanti-rabbit (P31430, Pierce) was used as a 1:5000 dilution. The luminescent signal was visualized by ECL using BioMax MR film (Kodak, http://www.kodak.com).

For mass spectrometry analysis, protein extracts were spun for $10 \mathrm{~min}$ at $12,000 \mathrm{~g}$, and $1 \mathrm{ml}$ supernatant was added to $100 \mu \mathrm{l}$ bed volume of Streptavidin Sepharose High Performance beads (GE Healthcare). Protein extracts were incubated in a rotator for $3 \mathrm{~h}$ at $4^{\circ} \mathrm{C}$, and washed four times with immunoprecipitation buffer (25 mM Tris- $\mathrm{HCl}, \mathrm{pH} 7.5,1 \mathrm{mM}$ EDTA, $150 \mathrm{mM}$ $\mathrm{NaCl}, 10 \%$ glycerol, and $5 \mathrm{mM} \mathrm{DTT}$, and $0.15 \%$ Nonidet P-40). Elution was performed twice with two bed volumes of washing buffer containing $4 \mathrm{mM}$ D-biotin (Sigma-Aldrich). $400 \mu \mathrm{l}$ eluted fractions were pooled and precipitated with trichloroacetic acid. Pellets were washed with $100 \%$ acetone at $-20^{\circ} \mathrm{C}$. $40 \mu \mathrm{l}$ samples were mixed with Laemmli sample buffer for MS and loaded on 12\% SDS-PAGE gels cased in Hoefer Might Small SE250 mini gel equipment (Amersham Biosciences, AB, Uppsala). After gel electrophoreses Coomassie PageBlue ${ }^{\mathrm{TM}}$ (Fermentas) staining was used to visualize the proteins.

\section{MASS SPECTROMETRY}

The protein bands corresponding to the mass of the expected Avr2 monomer and dimer were sliced from the Coomassie stained gel. In-gel digestion was performed as described by Rep et al. (2002). The peptides obtained after the digestion were analyzed by MALDI-TOF/TOF MS as described by Krasikov et al. (2011). Acquired spectra were then searched with Mascot (Matrix Science, UK) against a Fol database. The Fol protein database used for the analysis was obtained from Fusarium Comparative Genome website (http://www.broadinstitute. org/annotation/genome/fusarium_group/MultiHome.html) and supplemented by adding the sequences of known Six proteins that are not annotated in the public database. To identify the plant proteins, all spectra were also searched against a custom Solanaceae EST database from plant-assembled transcripts (http://plantta.jcvi.org/).

\section{YEAST TWO-HYBRID}

The matchmaker GAL4 two-hybrid system and yeast strain PJ694a were used for analyzing protein interactions. Yeast transformation was performed using lithium-acetate and polyethylene glycol 3350 as described (Gietz and Woods, 2002). Eight colonies were picked and transferred from the MM-WL plates, lacking Trp and Leu, to a fresh MM-WL plate and incubated for 5 days at $30^{\circ} \mathrm{C}$. Next, one colony per combination was re-suspended in $25 \mu l 0.9 \% \mathrm{NaCl}$ and $6 \mu \mathrm{l}$ was spotted on MM-WL, MM-HWL, MM-AWL, and MM-HWL plates containing $3 \mathrm{mM} 3$-amino1,2,4-triazole. After 5 days incubation at $30^{\circ} \mathrm{C}$, the plates were checked for growth and photographed.

\section{CO-IMMUNOPRECIPICATION}

For Co-IP experiments, total proteins were extracted from $N$. benthamiana leaves, as described above, $36 \mathrm{~h}$ after infiltrating with A. tumefaciens GV3101 containing either SLD:: $\triangle \mathrm{sp} A V R 2-$ HASBP or pGWB451:: $\triangle \mathrm{sp} A V R 2$ or a mixture of both A. tumefaciens strains. Immunoprecipication was performed as described above. A portion of the supernatant was reserved as input sample. $20 \mu \mathrm{l}$ immunoprecipicated samples and $40 \mu \mathrm{l}$ input samples were resuspended in $1 \times$ SDS-PAGE loading buffer and loaded on $12 \%$ SDS-PAGE gels. Next, the gels were subjected to immunoblotting using anti-HA peroxidase at dilution ratio 1:3000 (clone 3F10; Roche), and anti-GFP at dilution ratio 1:3000 (Invitrogen, VXA6455).

\section{CONFOCAL MICROSCOPY}

Confocal microscopical analysis was performed with an LSM510 (Zeiss, Germany). Excitation of GFP was done at $488 \mathrm{~nm}$ with an Ar-ion laser and emission was captured with a $505-530 \mathrm{~nm}$ pass filter. Excitation of RFP occurred at $543 \mathrm{~nm}$ with a HeNe laser. The 590-620 nm filter captured emission. To monitor co-localization RFP was excited at $543 \mathrm{~nm}$ and GFP at $488 \mathrm{~nm}$ or YFP at $514 \mathrm{~nm}$. 
GFP and YFP emission was captured with a 505-530 nm filter and RFP with a 565-615 nm filter. Images were scanned eight times.

\section{Agrobacterium-MEDIATED TRANSIENT TRANSFORMATION OF Nicotiana benthamiana}

A. tumefaciens strain GV3101(pMP90) (Koncz and Schell, 1986) was transformed with binary constructs as described previously (Takken et al., 2004). Agrobacterium-mediated transient transformation was performed according to methods described by Ma et al. (2012). Briefly, the agrobacteria were grown to an absorbance of 0.8 at $600 \mathrm{~nm}$ in LB-mannitol medium $\left(10 \mathrm{gl}^{-1}\right.$ tryptone, $5 \mathrm{gl}^{-1}$ yeast extract, $2.5 \mathrm{gl}^{-1} \mathrm{NaCl}, 10 \mathrm{gl}^{-1}$ mannitol) supplemented with $20 \mu \mathrm{m}$ acetosyringone and $10 \mathrm{~mm} \mathrm{MES} \mathrm{pH}$ 5.6. Cells were pelleted by centrifugation at $4000 \mathrm{~g}$ at $20^{\circ} \mathrm{C}$ for $20 \mathrm{~min}$ and then resuspended in infiltration medium $(1 \times \mathrm{MS}$ salts, $10 \mathrm{~mm}$ MES pH 5.6, 2\% w/v sucrose, $200 \mu \mathrm{m}$ acetosyringone). Infiltration was done in $N$. benthamiana leaves at an absorbance of 0.1 (for $I-2$ constructs) or 0.5 (for AVR 2 constructs) of 4-5-weeks-old plants.

\section{PLASMOLYSIS}

For plasmolysis, a plasma membrane marker labeled with YFP (ZmHVR-YFP) (Ma et al., 2012) and Avr2-RFP were co-infiltated in $N$. benthamiana leaves. Two days after infiltration, small infiltrated leaf pieces were collected and treated with $800 \mathrm{mM}$ mannitol for $30 \mathrm{~min}$ to induce plasmolysis. Subsequently, the pieces were mounted in $30 \%$ glycerol on a glass slide for microscopy.

\section{RESULTS \\ AVR2 IS PREDOMINANTLY EXPRESSED IN XYLEM-COLONIZING FUNGAL HYPHAE}

To determine at which stage of infection AVR2 is expressed, a Fol strain carrying an AVR2-promoter-reporter construct was created. mRFP was used as reporter and the $\mathrm{pAVR2:RFP}$ construct was transformed into a Fol-pAVR3:GFP strain. In this strain the coding sequence for Avr3 has been replaced by GFP encoding Green Fluorescent Protein (Van Der Does et al., 2008). The advantage of employing the Fol-pAVR3:GFP strain is that GFP can be used to monitor the growth of Fol in roots, as the AVR3 gene is specifically expressed inside roots (Van Der Does et al., 2008). The pAVR2:RFP construct was designed to facilitate its integration into the $A V R 2$ locus by homologous recombination (see Materials and Methods) to ensure expression from the native locus, avoiding position effects. The double transformant was used to inoculate ten-days-old tomato seedlings grown hydroponically (Van Der Does et al., 2008). Expression of both reporter genes was studied in a time-course analysis by visualizing the RFP and GFP signals in inoculated roots using confocal microscopy. Figure 1 shows that, at one-day post inoculation, only few of the germinated spores penetrating the roots display RFP florescence (AVR2 promoter activity), whereas a GFP signal (AVR3 promoter activity) is present in many germinating spores penetrating the roots. This observation confirms the earlier finding that expression of $A V R 3$ is induced upon contact with tomato roots (Van Der Does et al., 2008), and shows that in the majority of hyphae that colonize the root cortex AVR2 is not expressed. Two days after

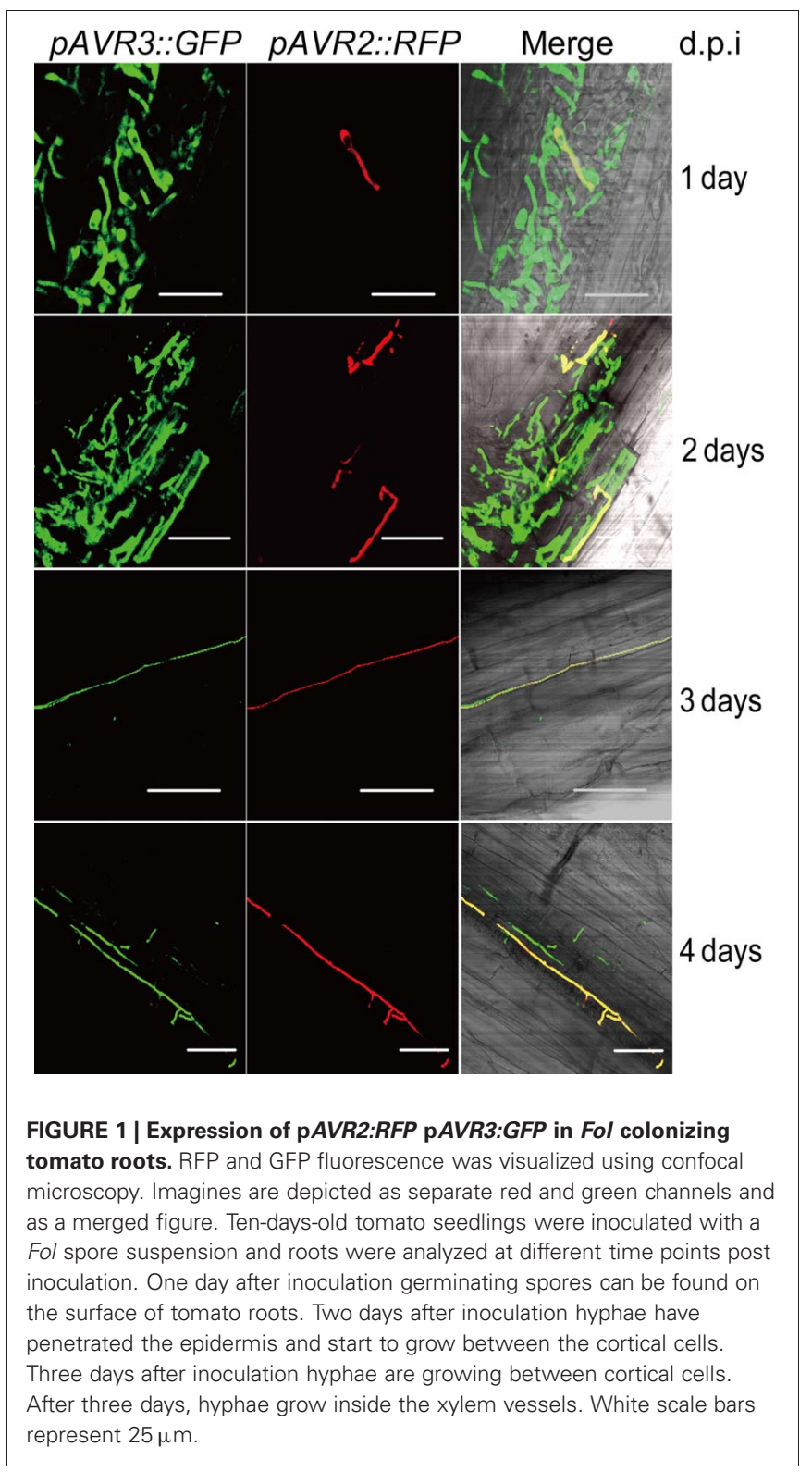

inoculation an RFP signal was still only detectable in a very limited number of hyphae or spores (Figure 1). At three days after inoculation red fluorescence was visible in some of the hyphae growing between the cortical cells (Figure 1), but the majority of the green fluorescent hyphae did not show red fluorescence. At stages later than three days after inoculation, RFP and GFP double fluorescent fungal hyphae were frequently found growing inside xylem vessels (Figure 1), demonstrating that AVR2 is highly expressed at this stage of infection. However, still not all hyphae express both genes at this stage and frequently hyphae were observed that contained only GFP (or, sometimes, RFP). From these observations we conclude that upon contact with tomato roots and during early stages of infection, expression of $A V R 3$ precedes that of $A V R 2$. From three days after inoculation and onward high expression of both AVR3 and AVR2 
was found in hyphae growing in the xylem vessels of tomato roots.

\section{Avr2 LOCALIZES TO THE CYTOSOL AND NUCLEUS OF PLANT CELLS}

To examine the localization of Avr2 in plant cells, A. tumefaciens harboring either full length AVR2 C-terminally fused to RFP or $A V R 2$ lacking its signal peptide $(\triangle \mathrm{sp} A V R 2)$ fused to RFP, was infiltrated in N. benthamiana leaves. The localization of Avr2-RFP and $\triangle$ spAvr2-RFP was then examined by confocal microscopy. The red fluorescence originating from the wild-type Avr2-RFP fusion was mainly found in the apoplastic space (Figure 2A, left panel, arrows). To confirm an apoplastic localization, and to exclude the possibility that Avr2 was tethered to the plasma membrane or cell wall, the AVR2-RFP construct was co-expressed with a plasma membrane marker (ZmHVR-YFP) and the plant cells were plasmolysed before microscopical analysis. As shown in Figure 2B, the yellow fluorescence from the ZmHVR-YFP protein is specifically localized at the plasma membrane flanking the diffuse red signal from Avr2-RFP, confirming the apoplastic localization of the latter (Figure 2B, right panel, arrows). The dispersed RFP signal suggests that Avr2 is secreted into the apoplast and diffuses between the plant cells. In contrast, the $\Delta$ spAvr2-RFP protein lacking its signal peptide localized inside

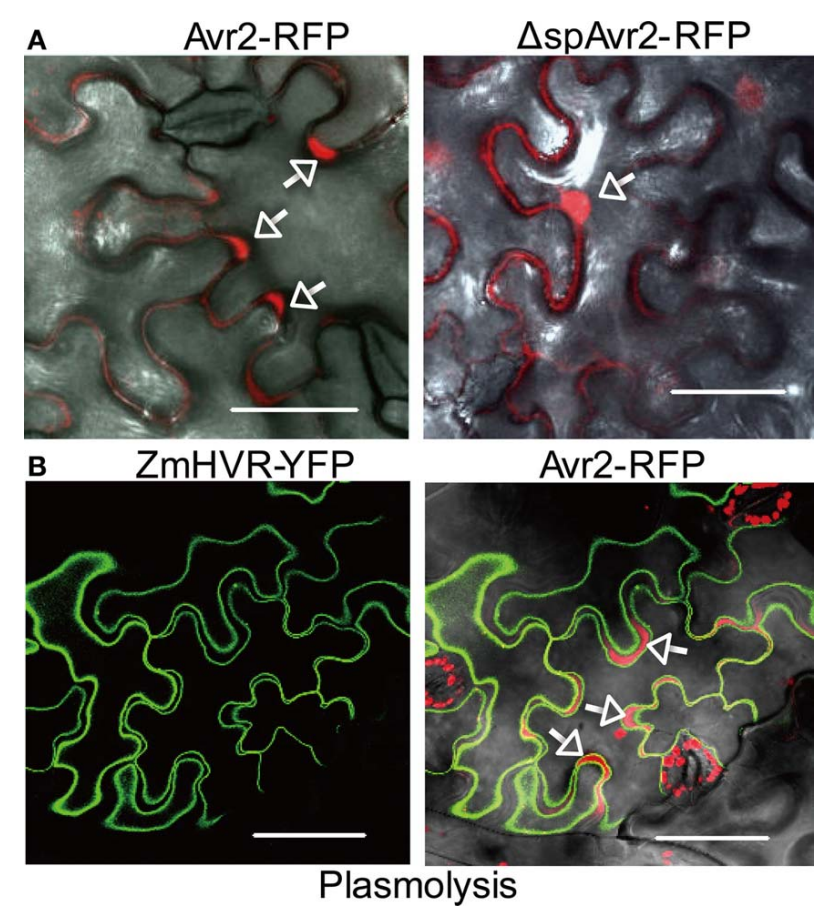

FIGURE 2 | Avr2 localizes in the cytosol and nucleus of $\boldsymbol{N}$. benthamiana cells after agroinfiltration. (A) Confocal images of mesophyll cells in $N$. benthamiana leaves $36 \mathrm{~h}$ after agroinfiltration with Avr2-RFP or $\triangle$ spAvr2-RFP lacking its signal peptide for secretion. White arrows indicate the apoplastic spaces. (B) Transient co-expression of Avr2-RFP and the plasma membrane marker ZmHVR-YFP in epidermal cells of $N$. benthamiana after plasmolysis. Avr2-RFP is clearly visible in the apoplastic spaces (arrows) that are enlarged due to plasmolysis. The white scale bars represent $25 \mu \mathrm{m}$. the plant cells. Here the fusion protein was found in the cytosol and the nucleus (Figure 2A, right panel, arrow). The nuclear localization of Avr2 can clearly be seen by the exclusion of the fluorescent protein from the nucleolus - more easily visible using a GFP-tagged Avr2 protein.

\section{NUCLEAR LOCALIZED Avr2 IS REOUIRED TO TRIGGER I-2-DEPENDENT CELL DEATH IN $\mathbf{N}$. benthamiana}

To determine at which subcellular localization Avr2 is recognized by I-2, $\triangle s p A V R 2$ was fused to either a nuclear import signal (NLS) at its N-terminus, or a NES at its C-terminus. A NLS targets the protein to the nucleus whereas the NES translocates Avr2 from the nucleus to the cytoplasm, reducing its nuclear concentration (Kalderon et al., 1984). To examine whether the localization signals are functional, the $\triangle s p A V R 2$ variants were C-terminally fused to GFP and expressed in $N$. benthamiana leaves using agroinfiltration. At $36 \mathrm{~h}$ after infiltration, green fluorescence was imaged using confocal microscopy. As observed before, wild-type Avr2, lacking its signal peptide $(\Delta s p)$ and fused to GFP, localized in both cytosol and nucleus (Figure 3A, arrow). NLS tagged Avr2 (NLS- $\triangle$ spAvr2-GFP) was only detected in the nucleus and not in the cytoplasm (Figure 3A, arrows). In contrast, the NES tagged Avr2 ( $\Delta$ spAvr2-NES-GFP) protein was found in both the cytoplasm and the nucleus albeit at a lower concentration as the $\triangle$ spAvr2-GFP control (Figure 3A). So, although the NES translocates Avr2 from the nucleus it does not exclude nuclear entry. To further reduce the amount of Avr2 in the nucleus the NEScontaining Avr2 protein was fused to a CBL1 (Myristoylation signal) motif at its $\mathrm{N}$-terminus to tether it to the plasma membrane, preventing nuclear entry. As a negative control an Avr2 fusion with both a mutated CBL1 (cbl1) and a mutated NES was made. Both constructs were expressed in $N$. benthamiana leaves using agroinfiltration and green fluorescence was imaged using confocal microscopy. The CBL1 and NES tagged Avr2 (CBL1$\triangle$ spAvr2-NES-GFP) protein was found exclusively at the plasma membrane and not in the nucleus (Figure 3A). The Avr2 variant carrying the cbl1 and nes signals (cbl1- $\Delta$ spAvr2-nes-GFP) displayed a distribution similar as $\Delta$ spAvr2. Immunoblotting showed that all $\Delta$ spAvr2-GFP fusion proteins accumulate at similar levels (Figure 3B). The majority of the proteins are intact, as bands were found at the expected size of $\sim 43 \mathrm{kDa}$. For the CBL1-Avr2-NES-GFP and cbl1-Avr2-nes-GFP extracts also some smaller bands were observed, which could be the consequence of limited proteolytic cleavage (Figure 3B).

We next utilized the above-described constructs to assess whether the enforced relocalization of Avr2 affected its ability to trigger I-2-mediated cell death. Thereto $I-2$ and the $A V R 2$ constructs carrying the various translocation signals were co-expressed in $N$. benthamiana leaves using agroinfiltration. Figure 3C shows that at approximately $36 \mathrm{~h}$ after co-infiltration nuclear localized NLS- $\Delta$ spAvr2-GFP triggered an I-2-dependent cell death response equivalent to that of $\Delta s p A v r 2$. In contrast, CBL1-Avr2-NES-GFP, which is retained in the plasma membrane, was unable to activate $I-2$ and induce cell death. Avr2 fused to the mutated (inactive) CBL1 and NES motifs triggered an $I-2$ specific cell death response similar to that of the $\Delta$ spAvr2 protein, showing that the mere extension of Avr2 with these 


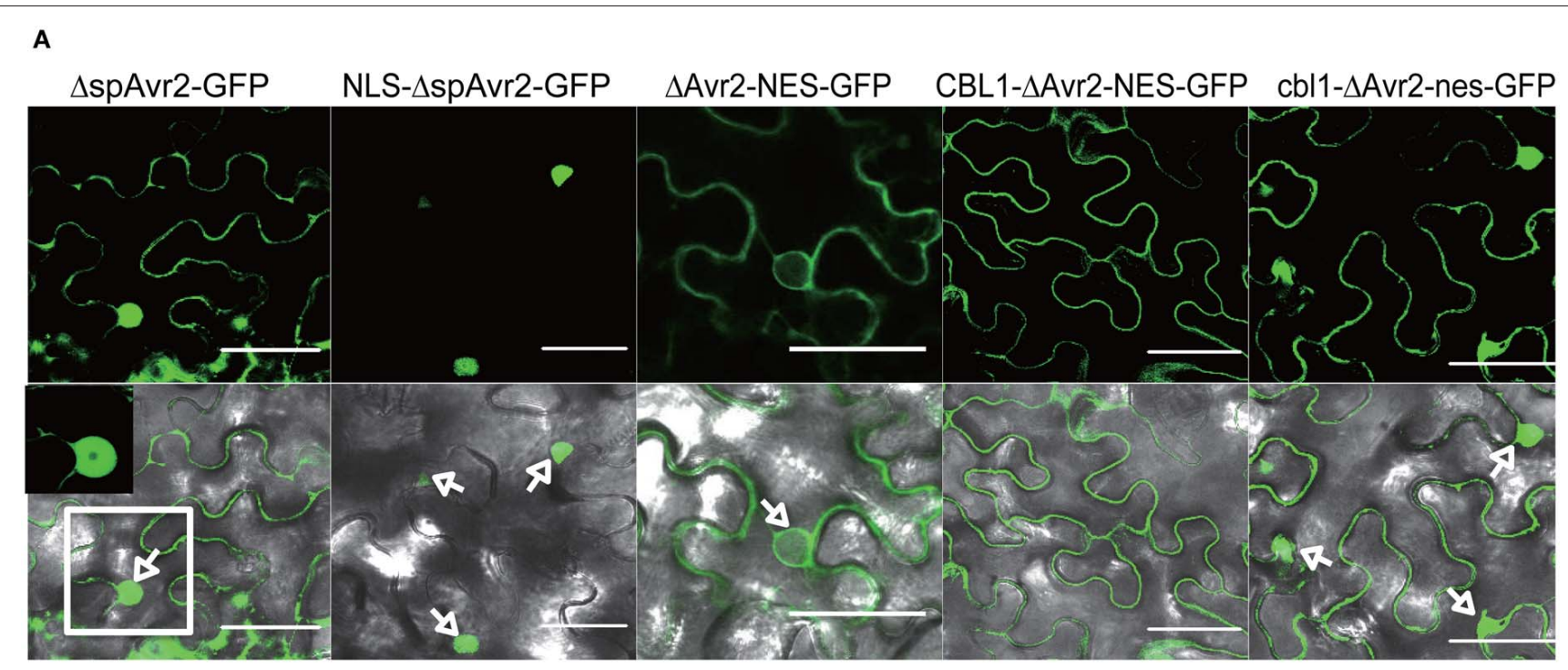

B

C
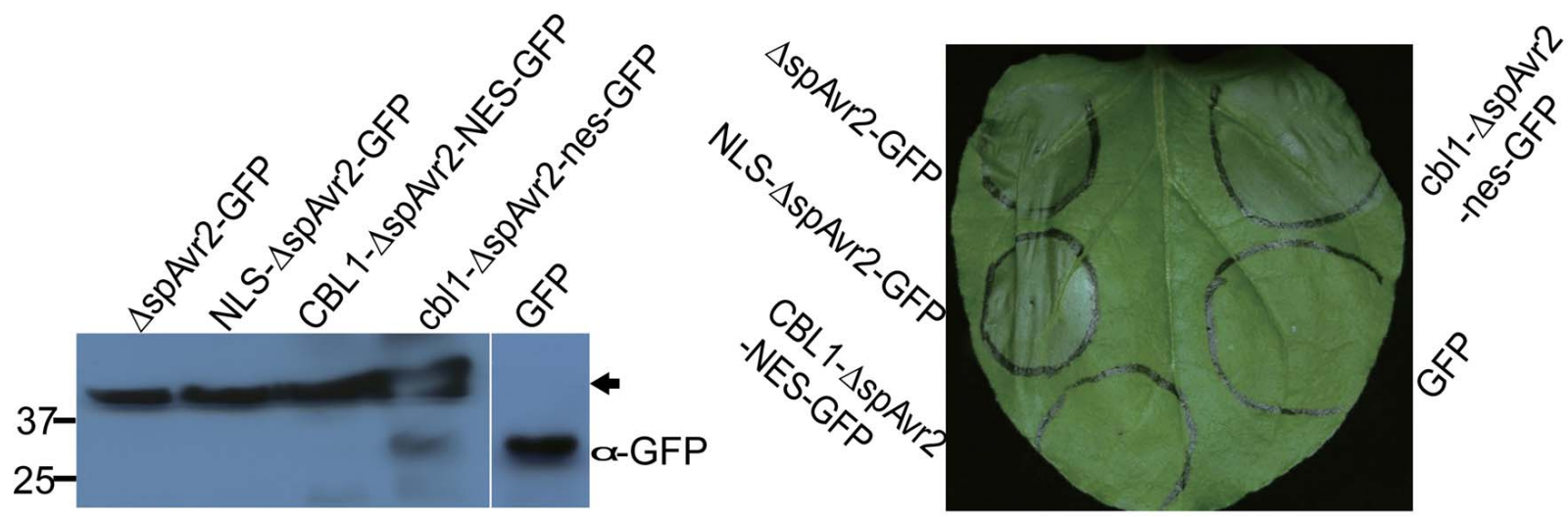

FIGURE 3 | Nuclear localization of Avr2 is required to trigger

I-2-dependent cell death in $\boldsymbol{N}$. benthamiana leaves. (A) Confocal image of $\Delta$ spAvr2-GFP, NLS- $\Delta$ spAvr2-GFP, $\Delta$ spAvr2-NES-GFP, CBL1- $\Delta$ spAvr2-NES-GFP, and cbl1- $\Delta$ spAvr2-nes-GFP in $N$. benthamiana leaves $36 \mathrm{~h}$ after

agroinfiltration. Arrows indicate the nucleus, top GFP channel, bottom GFP and bright field channels merged. (B) Immunoblot analysis of GFP-fusion proteins accumulating in planta $36 \mathrm{~h}$ after infiltration. Blots were probed with an $\alpha$-GFP antibody. The GFP alone control was used to assess the specificity of the antibody. Sizes in kDa are indicated on the left and an arrow indicates the $43 \mathrm{kDa}$ band of the full-length protein. (C) Nuclear localization is required for effector-triggered cell death. $N$. benthamiana leaves were co-infiltrated

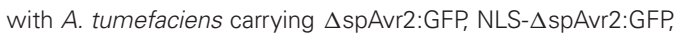

CBL1- $\Delta$ spAvr2-NES:GFP, cbl1- $\Delta$ spAvr2-nes:GFP, or GFP alone with a strain carrying an $1-2$ containing vector. A representative picture was taken three days after infiltration. Cell death is visible by tissue collapse of the infiltrated region. The white scale bars represent $25 \mu \mathrm{m}$. sequences did not interfere with its cell death inducing activity (Figure 3C). Co-expression of I-2 with the NES-tagged Avr2 induced a cell death response comparable to that of co-expression with cbl1-Avr2-nes-GFP protein and wildtype Avr2 (data not shown) consistent with the similar subcellular distribution pattern of the latter proteins. In summary, these results indicate that a nuclear localization of Avr2 is required to trigger I-2-dependent cell death.

\section{THE N-TERMINAL REGION OF Avr2 IS DISPENSABLE TO TRIGGER I-2-MEDIATED CELL DEATH}

To define the minimal region of Avr2 required to trigger I2-dependent cell death, two N-terminally truncated and one C-terminally truncated Avr2 protein was generated. To assist demarcation of the Avr2 truncations, PSIPRED (Buchan et al., 2010) was used to predict the secondary structure of the Avr2 protein (Figure 4A). Based on this prediction, the following variants were constructed: Avr $2 \Delta 37$, in which the first predicted random coil downstream of the signal peptide was deleted; Avr $2 \Delta 40$, a slightly extended deletion that includes the first cysteine; and Avr2CT $\Delta 11$, which lacks the last predicted $\beta$-strand at its C-terminus (Figure 4B). Both wild type and the three variants were equipped with a C-terminal TAP-tag.

A. tumefaciens strains containing plasmids encoding these truncated AVR2-TAP constructs were co-infiltrated with an A. tumefaciens strain harboring $I-2$ into $N$. benthamiana leaves. Expression of $\triangle s p A V R 2-T A P$ together with $I-2$ served as a positive control, and $I-2$ together with an GFP containing vector as 
A

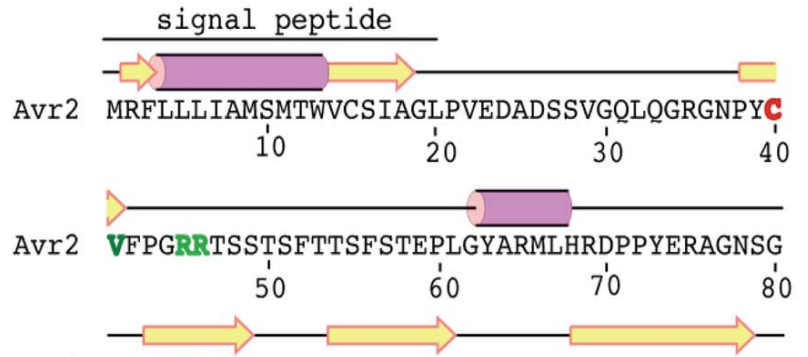

Avr2 LNHRIYERSRVGGLRTVIDVAPPDGHQAIANYEIEVRRIP 9'0 $100 \quad 110 \quad 120$

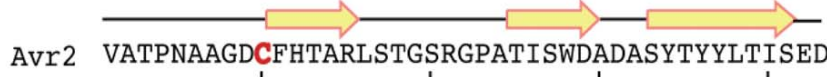
$\begin{array}{llll}130 & 140 & 150 & 160\end{array}$

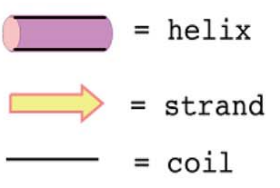

C

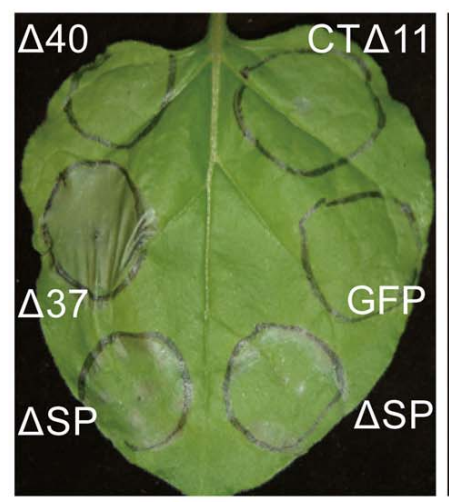

$24 \mathrm{~h}$

$36 \mathrm{~h}$
B

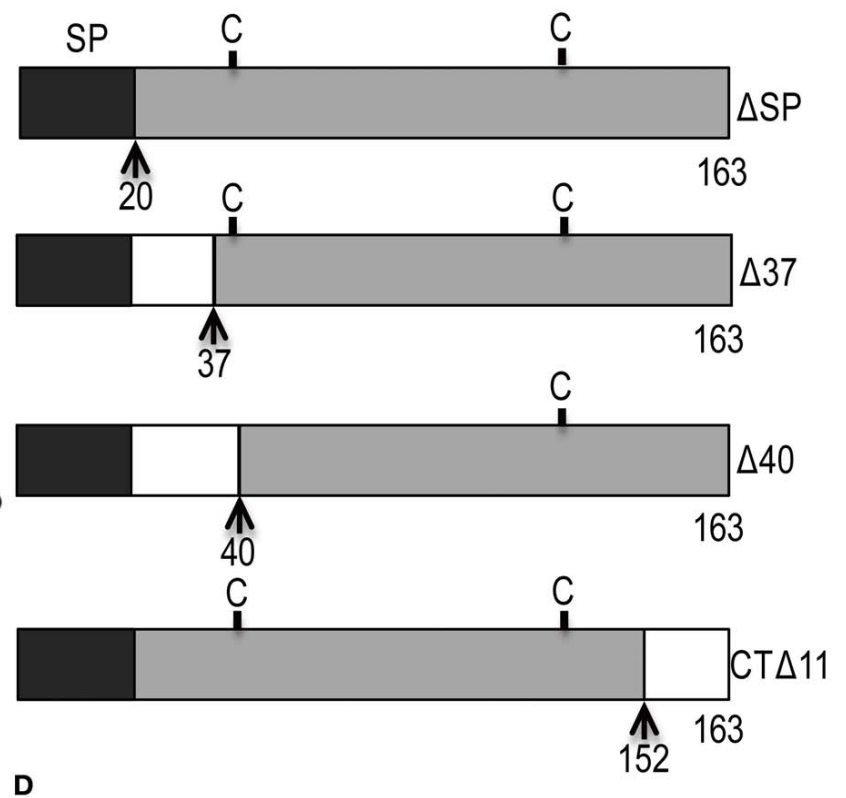

D
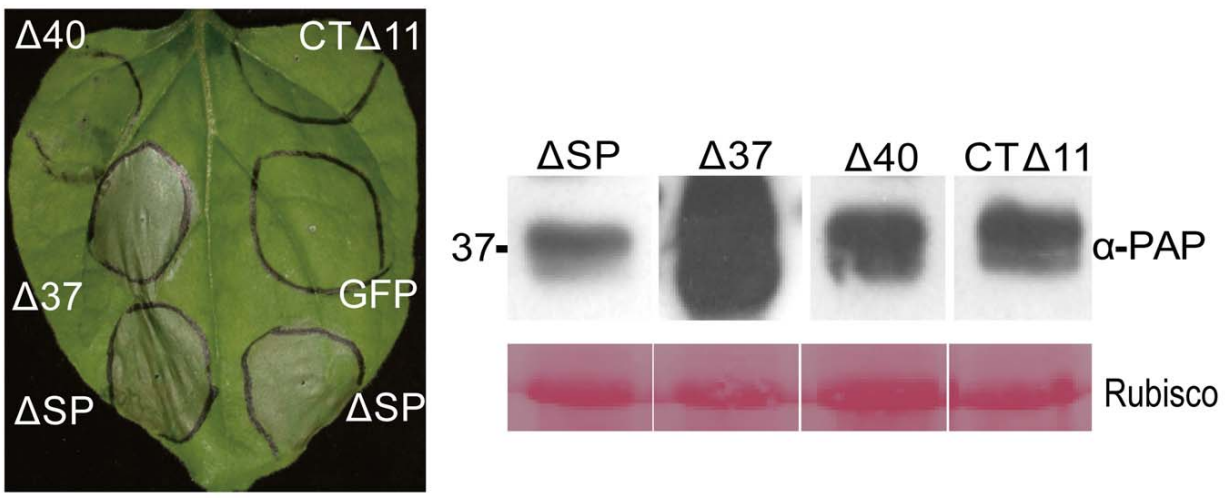

FIGURE 4 | A small $\mathrm{N}$-terminal region of Avr2 is dispensable for I-2-dependent cell death. (A) Secondary structure prediction of Avr2. The two cysteine residues are marked red. The three polymorphisms in 1-2-breaking ( $F o l$ race 3) Avr2 variants are marked green.

(B) Schematic diagram showing the Avr2 truncations. The signal peptide is shaded dark, $\mathrm{C}$ indicates a cysteine residue; $\mathrm{N}$ - and C-terminal truncation sites are indicated by dashed lines and arrows along with the corresponding amino acid number. (C) $N$. benthamiana leaves were co-infiltrated with $A$. tumefaciens cultures containing AVR2 truncations and 1-2. The left panel shows a leaf photographed $24 \mathrm{~h}$ after infiltration and the right panel a leaf photographed $36 \mathrm{~h}$ after infiltration. (D) Immunoblot of proteins extracted from agroinfiltrated $N$. benthamiana leaves expressing Avr2 truncations fused C-terminally to a TAP tag. Leaves were harvested $36 \mathrm{~h}$ after infiltration and analyzed by immunoblotting using an anti-PAP antibody recognizing the TAP tag ( $\alpha$-PAP). Ponceau $S$ staining of Rubisco (lower panel) is shown as a measure of the amount of protein loaded in each lane. Sizes in $\mathrm{kDa}$ are indicated on the left. a negative control. Compared to $\Delta \mathrm{spAvr} 2, \operatorname{Avr} 2 \Delta 37$ induced a much faster and stronger cell death response (Figure 4C). I-2dependent cell death triggered by Avr2 $\Delta 37$ was observed as early as $20-24 \mathrm{~h}$ after infiltration, whereas cell death induced by Avr2 did not appear until 10-12 h later. Expression of the two other truncated variants, Avr $2 \Delta 40$ and Avr2CT $\Delta 11$, did not induce I-2-dependent cell death (Figure 4C). Immunoblotting analysis demonstrated that all truncated proteins accumulated at similar levels, except the Avr2 $\Delta 37$ truncation that accumulated in much higher amounts (Figure 4D). Hence, the inability of Avr $2 \Delta 40$ and CT $\Delta 11$ to trigger $I$-2-mediated cell death is not due to a lack of protein accumulation. The high accumulation of Avr $2 \Delta 37$ might be correlated with its ability to trigger a faster and stronger cell death response. Based on these observations, we concluded that Avr2 can be functionally divided into two parts, a small Nterminal part that is not required for I-2-mediated cell death and a large C-terminal region that includes the two cysteines and is indispensable for this activity.

\section{Avr2 HOMODIMERIZES in vivo}

Immunobloting of agroinfiltrated $N$. benthamiana leaves expressing a C-terminally human influenza HA and streptavidin-binding 


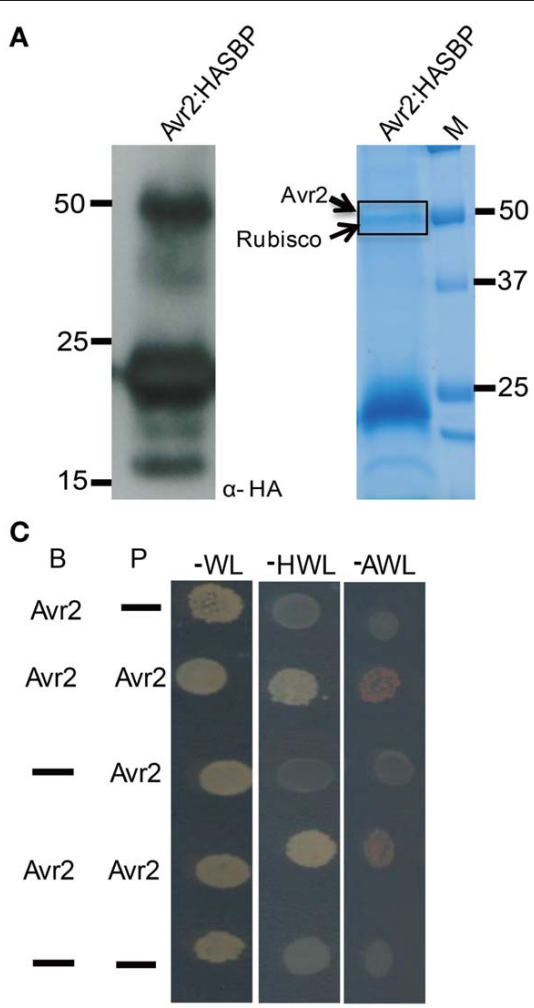

FIGURE 5 | Avr2 forms homodimers in planta and in yeast.

(A) Immunoblot probed with anti-HA showing that Avr2-HA-SBP is detected at the expected apparent molecular weight of $\pm 25 \mathrm{kDa}$ as well as in a $\pm 50 \mathrm{kDa}$ band. Avr2-HA-SBP was expressed in Agrobacterium-infiltrated $N$. benthamiana leaves and subsequently affinity-purified using the SBP tag. The purified protein was size separated using SDS-PAGE and the gel was stained with Colloidal Coomassie. The dashed rectangle indicates the section used for mass spectrometric analysis and the identified proteins are indicated on the left. Positions and sizes of the molecular weight marker are shown. (B) Immunoprecipitation of Avr2 from total plant protein extracts. Proteins extracted from $N$. benthamiana leaves expressing pairwise combinations of Avr2 C-terminally tagged with either HASBP or GFP. The fusion proteins were immunoprecipitated using streptavidin beads. Total extracted proteins (input)
B

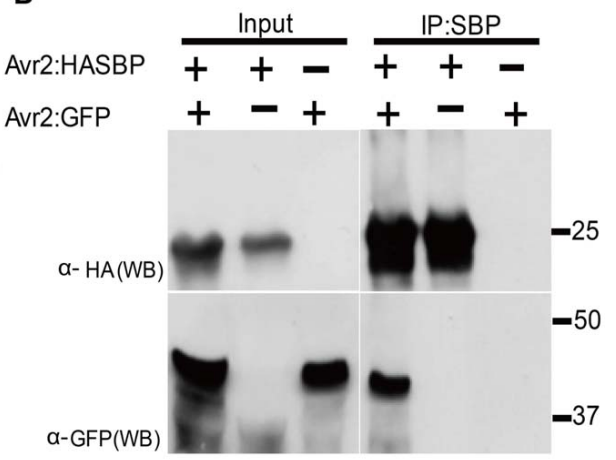

D

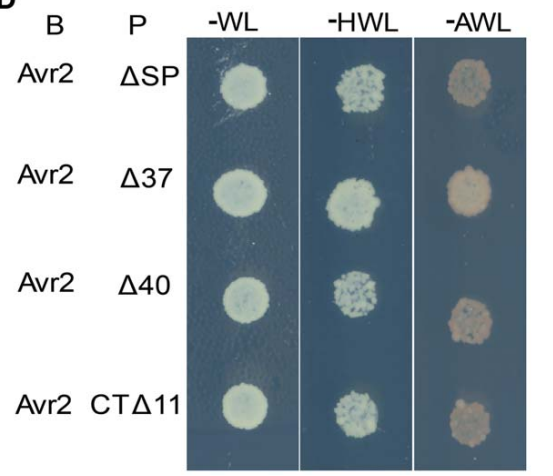

and immunoprecipitated proteins (IPS) were analyzed by immunoblotting by probing with either anti-HA ( $\alpha-\mathrm{HA}$; upper) or anti-GFP ( $\alpha$-GFP; lower). Positions and sizes of protein mass makers are shown. (C) Growth of yeast strain pJ694a transformed with prey (P) constructs containing AVR2 or empty vector (-) and bait (B) constructs containing AVR2 or empty vector (-). All transformed yeasts could grow on minimal media lacking tryptophan and leucine $(-W L)$ due to presence of the bait and prey plasmids. Only yeast containing both Avr2 as prey and bait was able to grow on selection plates lacking histidine, tryptophan and leucine $(-\mathrm{HWL})$, and the more stringent selection medium lacking alanine, tryptophan and leucine (-AWL). Neither empty bait nor prey or Avr2 alone in combination with an empty vector could grow on the selection plates. (D) All Avr2 truncations interacted with wild-type Avr2 in yeast. peptide (SBP) double-tagged Avr2 fusion protein (Avr2-HASBP), frequently revealed an additional $\sim 50 \mathrm{kDa}$ band, i.e., twice the molecular mass of the Avr2-HASBP protein (Figure 5A). Since this larger product cross-reacted with the HA antibody it likely contains the Avr2-HASBP protein incorporated in a larger complex. To identify the constituents of this complex mass spectrometric analysis was performed. Avr2-HASBP containing complexes were affinity purified using SBP beads from a protein extract isolated from agroinfiltrated $N$. benthamiana leaves transiently expressing AVR2-HASBP. Next, the purified Avr2 protein complexes were size-separated on SDS-PAGE and the region corresponding to the $\sim 50 \mathrm{kDa}$ product was cut out from the gel (Figure 5A). The proteins in the slice were in-gel digested and subjected to mass spectrometric analysis. Four peptides matching to Avr2 and ten peptides corresponding to Rubisco were identified in the peptide list (data not shown). Since the latter is a likely contaminant, the absence of other proteins raised the possibility that Avr2-HASBP might homodimerize, giving rise to the $50 \mathrm{kDa}$ product.

To confirm the ability of Avr2 to physically self-interact in planta, co-immunoprecipitation experiments were performed. Two different AVR2 constructs were used that each carry a different epitope tag: HASBP or GFP. Following co-agroinfiltration of these constructs into $N$. benthamiana leaves, the Avr2HASBP protein was pulled down using SBP affinity beads and co-purification of the other was assessed using its GFP tag. Figure 5B shows that GFP-tagged Avr2 co-precipitates with HASBP-tagged Avr2 when both genes were co-expressed in $N$. benthamiana leaves, demonstrating that Avr2 has the ability to multimerize. To further test this, a yeast-two hybrid experiment was conducted using Avr2 both as bait and prey. As shown in Figure 5C, Avr2 interacts with itself, as yeast transformed both with bait and prey plasmids harboring Avr2 grew on the selective-HWL and also on the more stringent-AWL medium. Yeast co-transformed with Avr2 and empty bait or prey plasmid 
was unable to grow on the selection plates (Figure 5C). Together, these data strongly suggest that Avr2 can form dimers in planta and in yeast.

To determine whether dimerization is correlated with the ability of Avr2 to activate I-2, the dimerization capacity of the three truncated Avr2 variants (Figure 4) was examined using yeast twohybrid assays. As shown in Figure 5D all constructs supported growth on selective-HWL and -AWL medium, suggesting that the central region of Avr2 of 104 amino acids (aa 40-144) is sufficient for dimerization. Since Avr $2 \Delta 40$ and Avr2CT $\Delta 11$ are not capable of activating I-2 it can be concluded that dimerization of the central region alone is not sufficient to induce I-2-mediated cell death.

\section{DISCUSSION}

Expression of AVR2 was rarely observed during early stages of infection when the fungus colonizes the epidermis and invades the roots to grow between the cortical cells (Figure 1). However, during later stages of infection when the fungus colonizes the xylem vessels AVR2 expression could readily be detected (Figure 1). This expression pattern differs from that of AVR3 (SIX1), which was found to be expressed early upon infection and green fluorescence can be visualized already one-day post inoculation. The AVR3 gene continues to be expressed during later stages of infection [(Van Der Does et al., 2008) and Figure 1]. Notably, at these later stages many fungal hyphae could be observed that express both genes, but also hyphae were found that express only one of the two genes. The latter is surprising since previous studies showed that expression of most Six genes, including AVR3 (SIX1), and AVR2 (SIX3), depends on the presence of the same transcription factor, Sge1 (Six Genes Expression 1) (Michielse et al., 2009). The dissimilar expression of $A V R 2$ with $A V R 3$ indicates that expression of these genes is not solely regulated by Sge1, but is likely also controlled by other factors. It will be interesting to analyse the expression profile of other effector genes during infection and to compare these to AVR3 and $A V R 2$ to identify whether they are controlled in similar fashion. The relatively late expression of AVR2 suggests that I-2-mediated resistance occurs relative late in infection, e.g., when the fungus colonizes the xylem vessels. $I$-2-mediated resistance acting in the xylem tissues is in agreement with (1) the expression of I-2 in the vasculature and its lack of expression in cortical root cells (Mes et al., 2000), (2) the presence of the Avr2 protein in the xylem sap of tomato (Houterman et al., 2009), and (3) the observation that in an I-2 plant Fol is able to colonize the cortical root cells and to reach the xylem vessels which it can colonize to an extent (Rep, pers. communication).

Deletion of the N-terminal 17 amino acids $(\Delta 37)$ of Avr2 did not impair its ability to trigger I-2-dependent cell death. Actually, upon agrotransformation the truncated protein induced a faster and stronger cell death response than full length Avr2 protein, which correlated with an increased accumulation of the truncated protein (Figures 4C and D). The mechanism underlying the higher accumulation of this truncated protein is unknown, but the truncated form resembles the shorter forms found in the xylem sap. On 2D protein gels of xylem sap from infected tomato plants Avr2 localizes in at least three spots ranging in size from
11 to $14 \mathrm{kDa}$. Mass spectrometric analysis of these spots revealed that the smallest form of Avr2 in xylem sap has a N-terminal deletion similar to that of $\Delta 37$ (Houterman et al., 2007). The removal of these 17 aa might be due to $\mathrm{N}$-terminal processing by plant proteases in xylem sap. An extended deletion removing 20 amino acids at the $\mathrm{N}$-terminus encompassing the first cysteine after the signal peptide $(\Delta 40)$ completely abolished the ability of Avr2 to trigger I-2-dependent cell death (Figure 4C). Since there are two cysteine residues present in Avr2 (Figure 4A), it is possible that a disulfide bond is formed in the mature Avr2 protein. Deletion of the cysteine would disrupt this bond, potentially affecting protein structure. However, the protein apparently retains at least part of its fold, as the mutant is still able to interact with wild-type Avr2 in yeast. Alternatively, the cysteine at position 40 might be part of a motif that is required for I-2-mediated recognition. Support for this hypothesis is the observation that Avr2 variants from race 3 strains of Fol that overcome I-2mediated resistance carry a mutation in one of three nearby residues; valine 41, arginine 45, or arginine 46 (Houterman et al., 2009). Possibly, these residues together form an epitope that is recognized by I-2. A C-terminal deletion also abolished I-2-mediated recognition, but retained the proteins' ability to interact with wild-type Avr2 in yeast (Figure 5D). Together, these data show that dimerization alone is insufficient to activate I-2, and that also the C-terminus contains sequences required for I2-mediated recognition (Figure 5D). The central part that can dimerize contains the "RIYER" sequence motif that was identified by Kale and co-workers as an "RXLR-like" motif that could be involved in entry of this effector in plant cells (Kale et al., 2010). A truncated Avr2 protein, consisting of the N-terminal half of the protein containing this domain, was taken up by soybean root cells whereas various RIYER mutants were not (Kale et al., 2010). In many oomycete effectors mutations in the conserved RxLR motif abolish their uptake by host cells (Grouffaud et al., 2008). One proposed function for the RxLR motif is binding to phosphatidylinositol-3-phosphate (PI3P) present on the outer surface of the plant plasma membrane, enabling vesiclemediated endocytosis (Kale et al., 2010). An alternative function for the RXLR motif of an oomycete effector was recently proposed for AVR3a from Phythophthora infestans in which this region is required for homodimerization (Boutemy et al., 2011; Wawra et al., 2012). Whether the RIYER motif in Avr2 is also required for dimerization awaits elucidation of its $3 \mathrm{D}$ protein structure. Solving the structure will not only aid identification of surface localized residues involved in homodimerization, but could also reveal residues that mediate interaction with plant proteins.

Using a heterologous expression system, we demonstrated that nuclear localization of Avr2 is required to trigger an I2-dependent cell death response (Figure 3). Unfortunately, the subcellular localization of I-2 is unknown and its determination is hampered by the lack of sensitive antibodies and the loss of function of tagged I-2 variants (Tameling et al., 2002). A truncated I-2 protein, lacking its LRR domain, localizes in both the nucleus and the cytosol when expressed via agroinfiltration in $N$. benthamiana (manuscript in preparation). In addition, a potential NLS (RKHK) has been predicted in the CC domain of 
I-2 (Simons et al., 1998). These observations imply that I-2 could also be localized in the nucleus.

Proximity of an NLR to its recognized effector(s) is a likely prerequisite for its activation. Recent examples are Arabidopsis RPM1 that initiates signaling at the plasma membrane where its effectors AvrRpm1 and AvrB reside (Gao et al., 2011). Likewise, the potato R3a protein is activated only when it colocalizes with its cognate Phytophtora infestans effector $\mathrm{Avr} 3 \mathrm{a}^{\mathrm{KI}}$ at endosomal compartments (Engelhardt et al., 2012). Finally, the tobacco $\mathrm{Rx}$ protein needs to co-localize with the viral effector in the cytoplasm to become activated (Slootweg et al., 2010). The different sites for NLR activation could reflect the surveillance of diverse effector activities, which would imply a nuclear function for Avr2. Whether I-2 resistance signaling also requires its nuclear location remains to be investigated. A growing body of evidence suggest that nuclear or a nucleocytoplasmic localization for at least some $\mathrm{R}$ proteins, such as tobacco $\mathrm{N}$, potato $\mathrm{Rx}$, and barley Mla10 is essential for proper immune signaling (Burch-Smith et al., 2007; Slootweg et al., 2010; Tameling et al., 2010; Bai et al., 2012; Heidrich et al., 2012) [reviewed

\section{REFERENCES}

Alfano, J. R. (2009). Roadmap for future research on plant pathogen effectors. Mol. Plant Pathol. 10, 805-813.

Bai, S., Liu, J., Chang, C., Zhang, L., Maekawa, T., Wang, Q., et al. (2012). Structure-function analysis of barley NLR immune receptor MLA10 reveals its cell compartment specific activity in cell death and disease resistance. PLoS Pathog. 8:e1002752. doi: 10.1371/journal.ppat. 1002752

Batistic, O., Sorek, N., Schultke, S., Yalovsky, S., and Kudla, J. (2008). Dual fatty acyl modification determines the localization and plasma membrane targeting of CBL/CIPK Ca2+ signaling complexes in Arabidopsis. Plant Cell 20, 1346-1362.

Beckman, C. H. (2000). Phenolicstoring cells: keys to programmed cell death and periderm formation in wilt disease resistance and in general defence responses in plants? Physiol. Mol. Plant P 57, 101-110.

Boutemy, L. S., King, S. R., Win, J., Hughes, R. K., Clarke, T. A., Blumenschein, T. M., et al. (2011). Structures of Phytophthora RXLR effector proteins: a conserved but adaptable fold underpins functional diversity. J. Biol. Chem. 286, 35834-35842.

Buchan, D. W., Ward, S. M., Lobley, A. E., Nugent, T. C., Bryson, K., and Jones, D. T. (2010). Protein annotation and modelling servers at University College London. Nucleic Acids Res. 38, W563-W568.
Burch-Smith, T. M., Schiff, M., Caplan, J. L., Tsao, J., Czymmek, K., and Dinesh-Kumar, S. P. (2007). A novel role for the TIR domain in association with pathogen-derived elicitors. PLoS Biol. 5:e68. doi: 10.1371/journal.pbio.0050068

Chisholm, S. T., Coaker, G., Day, B., and Staskawicz, B. J. (2006). Hostmicrobe interactions: shaping the evolution of the plant immune response. Cell 124, 803-814.

De Jonge, R., Bolton, M. D., and Thomma, B. P. H. J. (2011). How filamentous pathogens co-opt plants: the ins and outs of fungal effectors. Curr. Opin. Plant Biol. 14, 400-406.

Deslandes, L., and Rivas, S. (2011). The plant cell nucleus: a true arena for the fight between plants and pathogens. Plant Signal. Behav. 6, 42-48.

Dodds, P. N., and Rathjen, J. P. (2010). Plant immunity: towards an integrated view of plant-pathogen interactions. Nat. Rev. Genet. 11, 539-548.

Dou, D., Kale, S. D., Wang, X., Jiang, R. H., Bruce, N. A., Arredondo, F. D., et al. (2008). RXLR-mediated entry of Phytophthora sojae effector Avrlb into soybean cells does not require pathogen-encoded machinery. Plant Cell 20, 1930-1947.

Ellis, J. G., Rafiqi, M., Gan, P., Chakrabarti, A., and Dodds, P. N. (2009). Recent progress in discovery and functional analysis of effector proteins of fungal and oomycete plant pathogens. Curr. Opin. Plant Biol. 12, 399-405. by Deslandes and Rivas (2011), Rivas (2012)]. Interestingly, the P. syringae effector AvrRps4 was found to trigger compartmentspecific immune responses in which nuclear localized AvrRps4 triggers RPS4-dependent resistance and cytoplasmic AvrRps4 induces cell death, implying that cell death and resistance signaling are independent processes (Heidrich et al., 2011). The barley resistance protein MLA10 also displays compartmentspecific immunity; the nuclear pool being involved in resistance and the cytoplasmic pool in triggering cell death (Bai et al., 2012). It will be interesting to determine whether Avr2-mediated cell death and resistance also require different locations for I-2 or whether both immune responses originate from the plant nucleus.

\section{ACKNOWLEDGMENTS}

We are gratefully to Harold Lemereis, Thijs Hendrix, and Ludek Tikovsky for plant care, and to Martijn Rep for stimulating discussions and critical reading of the manuscript. This work was financially supported by the CBSG, a NGI initiative, and the University of Amsterdam.

Engelhardt, S., Boevink, P. C., Armstrong, M. R., Ramos, M. B., Hein, I., and Birch, P. R. (2012). Relocalization of late blight resistance protein $\mathrm{r} 3 \mathrm{a}$ to endosomal compartments is associated with effector recognition and required for the immune response. Plant Cell 24, 5142-5158.

Gao, Z., Chung, E. H., Eitas, T. K., and Dangl, J. L. (2011). Plant intracellular innate immune receptor resistance to Pseudomonas syringae $p v$. maculicola 1 (RPM1) is activated at, and functions on, the plasma membrane. Proc. Natl. Acad. Sci. U.S.A. 108, 7619-7624.

Gietz, R. D., and Woods, R. A. (2002). Transformation of yeast by lithium acetate/single-stranded carrier DNA/polyethylene glycol method. Methods Enzymol. 350, 87-96.

Grouffaud, S., Van West, P., Avrova, A. O., Birch, P. R., and Whisson, S. C. (2008). Plasmodium falciparum and Hyaloperonospora parasitica effector translocation motifs are functional in Phytophthora infestans. Microbiology 154, 3743-3751.

Heidrich, K., Blanvillain-Baufume, S., and Parker, J. E. (2012). Molecular and spatial constraints on NB-LRR receptor signaling. Curr. Opin. Plant Biol. 15, 385-391.

Heidrich, K., Wirthmueller, L., Tasset, C., Pouzet, C., Deslandes, L., and Parker, J. E. (2011). Arabidopsis EDS1 connects pathogen effector recognition to cell compartmentspecific immune responses. Science 334, 1401-1404.
Houterman, P. M., Ma, L., Van Ooijen, G., De Vroomen, M. J., Cornelissen, B. J. C., Takken, F. L. W., et al. (2009). The effector protein Avr2 of the xylem-colonizing fungus Fusarium oxysporum activates the tomato resistance protein I-2 intracellularly. Plant J. 58, 970-978.

Houterman, P. M., Speijer, D., Dekker, H. L., De Koster, C. G., Cornelissen, B. J. C., and Rep, M. (2007). The mixed xylem sap proteome of Fusarium oxysporum-infected tomato plants. Mol. Plant Pathol. 8, 215-221.

Kalderon, D., Roberts, B. L., Richardson, W. D., and Smith, A. E. (1984). A short amino acid sequence able to specify nuclear location. Cell 39, 499-509.

Kale, S. D., Gu, B., Capelluto, D. G., Dou, D., Feldman, E., Rumore, A., et al. (2010). External lipid PI3P mediates entry of eukaryotic pathogen effectors into plant and animal host cells. Cell 142, 284-295.

Kamoun, S. (2006). A catalogue of the effector secretome of plant pathogenic oomycetes. Annu. Rev. Phytopathol. 44, 41-60.

Koncz, C., and Schell, J. (1986). The promoter of Tl-DNA gene 5 controls the tissue-specific expression of Chimeric genes carried by a novel type of Agrobacterium binary vector. Mol. Gen. Genet. 204, 383-396.

Krasikov, V., Dekker, H. L., Rep, M., and Takken, F. L. W. (2011). The tomato xylem sap protein XSP10 is required for full susceptibility to Fusarium wilt disease. J. Exp. Bot. 62, 963-973. 
Ma, L., Lukasik, E., Gawehns, F., and Takken, F. L. (2012). The use of agroinfiltration for transient expression of plant resistance and fungal effector proteins in Nicotiana benthamiana leaves. Methods Mol. Biol. 835, 61-74.

Maekawa, T., Kufer, T. A., and SchulzeLefert, P. (2011). NLR functions in plant and animal immune systems: so far and yet so close. Nat. Immunol. 12, 818-826.

Mes, J. J., Van Doorn, A. A., Wijbrandi, J., Simons, G., Cornelissen, B. J. C., and Haring, M. A. (2000). Expression of the Fusarium resistance gene $I-2$ colocalizes with the site of fungal containment. Plant J. 23, 183-193.

Michielse, C. B., and Rep, M. (2009). Pathogen profile update: Fusarium oxysporum. Mol. Plant Pathol. 10, 311-324.

Michielse, C. B., Van Wijk, R., Reijnen, L., Manders, E. M., Boas, S., Olivain, C., et al. (2009). The nuclear protein Sgel of Fusarium oxysporum is required for parasitic growth. PLoS Pathog. 5:e1000637. doi: 10.1371/journal.ppat.1000637

Nakagawa, T., Suzuki, T., Murata, S., Nakamura, S., Hino, T., Maeo, K., et al. (2007). Improved Gateway binary vectors: high-performance vectors for creation of fusion constructs in transgenic analysis of plants. Biosci. Biotechnol. Biochem. 71, 2095-2100.

Rafiqi, M., Gan, P. H., Ravensdale, M., Lawrence, G. J., Ellis, J. G., Jones, D. A., et al. (2010). Internalization of flax rust avirulence proteins into flax and tobacco cells can occur in the absence of the pathogen. Plant Cell 22, 2017-2032.

Rep, M., Dekker, H. L., Vossen, J. H., De Boer, A. D., Houterman, P. M., Speijer, D., et al. (2002).
Mass spectrometric identification of Isoforms of PR proteins in xylem sap of fungus-infected tomato. Plant Physiol. 130, 904-917.

Rep, M., Van Der Does, H. C., Meijer, M., Van Wijk, R., Houterman, P. M., Dekker, H. L., et al. (2004). A small, cysteine-rich protein secreted by Fusarium oxysporum during colonization of xylem vessels is required for I-3-mediated resistance in tomato. Mol. Microbiol. 53, 1373-1383.

Rivas, S. (2012). Nuclear dynamics during plant innate immunity. Plant Physiol. 158, 87-94.

Rohila, J. S., Chen, M., Cerny, R., and Fromm, M. E. (2004). Improved tandem affinity purification tag and methods for isolation of protein heterocomplexes from plants. Plant J. 38, 172-181.

Schornack, S., Van Damme, M. Bozkurt, T. O., Cano, L. M., Smoker, M., Thines, M., et al. (2010). Ancient class of translocated oomycete effectors targets the host nucleus. Proc. Natl. Acad. Sci. U.S.A. 107, 17421-17426.

Shames, S. R., and Finlay, B. B. (2012). Bacterial effector interplay: a new way to view effector function. Trends Microbiol. 20, 214-219.

Simons, G., Groenendijk, J., Wijbrandi, J., Reijans, M., Groenen, J., Diergaarde, P., et al. (1998). Dissection of the fusarium I2 gene cluster in tomato reveals six homologs and one active gene copy. Plant Cell 10, 1055-1068.

Slootweg, E., Roosien, J., Spiridon, L. N., Petrescu, A. J., Tameling, W., Joosten, M., et al. (2010). Nucleocytoplasmic distribution is required for activation of resistance by the potato NB-LRR receptor Rx1 and is balanced by its functional domains. Plant Cell 22, 4195-4215.
Spoel, S. H., and Dong, X. N. (2012). How do plants achieve immunity? Defence without specialized immune cells. Nat. Rev. Genet. 12, 89-100.

Takken, F., and Rep, M. (2010). The arms race between tomato and Fusarium oxysporum. Mol. Plant Pathol. 11, 309-314.

Takken, F. L., Van Wijk, R., Michielse, C. B., Houterman, P. M., Ram, A. F., and Cornelissen, B. J. (2004). A one-step method to convert vectors into binary vectors suited for Agrobacterium-mediated transformation. Curr. Genet. 45, 242-248.

Tameling, W. I. L., Elzinga, S. D. J. Darmin, P. S., Vossen, J. H., Takken, F. L. W., Haring, M. A., et al. (2002). The tomato R gene products I-2 and Mi-1 are functional ATP binding proteins with ATPase activity. Plant Cell 14, 2929-2939.

Tameling, W. I. L., Nooijen, C., Ludwig, N., Boter, M., Slootweg, E., Goverse, A., et al. (2010). RanGAP2 mediates nucleocytoplasmic partitioning of the NB-LRR immune receptor $\mathrm{Rx}$ in the Solanaceae, thereby dictating $\mathrm{Rx}$ function. Plant Cell 22, 4176-4194.

Thomma, B. P., Nurnberger, T., and Joosten, M. H. (2011). Of PAMPs and effectors: the blurred PTI-ETI dichotomy. Plant Cell 23, 4-15.

Tyler, B. M. (2009). Entering and breaking: virulence effector proteins of oomycete plant pathogens. Cell Microbiol. 11, 13-20.

Van Der Does, H. C., Duyvesteijn, R. G. E., Goltstein, P. M., Van Schie, C. C. N., Manders, E. M. M. Cornelissen, B. J. C., et al. (2008). Expression of effector gene SIX1 of Fusarium oxysporum requires living plant cells. Fungal Genet. Biol. 45, 1257-1264.
Wawra, S., Agacan, M., Boddey, J. A., Davidson, I., Gachon, C. M. Zanda, M., et al. (2012). Avirulence protein 3a (AVR3a) from the potato pathogen Phytophthora infestans forms homodimers through its predicted translocation region and does not specifically bind phospholipids. J. Biol. Chem. 287 38101-38109.

Whisson, S. C., Boevink, P. C., Moleleki, L., Avrova, A. O., Morales, J. G., Gilroy, E. M., et al. (2007). A translocation signal for delivery of oomycete effector proteins into host plant cells. Nature 450, 115-118.

Conflict of Interest Statement: The authors declare that the research was conducted in the absence of any commercial or financial relationships that could be construed as a potential conflict of interest.

Received: 07 February 2013; paper pending published: 28 February 2013; accepted: 27 March 2013; published online: 11 April 2013.

Citation: Ma L, Cornelissen BJC and Takken FLW (2013) A nuclear localization for Avr2 from Fusarium oxysporum is required to activate the tomato resistance protein I-2. Front. Plant Sci. 4:94. doi: 10.3389/fpls.2013.00094

This article was submitted to Frontiers in Plant-Microbe Interaction, a specialty of Frontiers in Plant Science.

Copyright (C) $2013 \mathrm{Ma}$, Cornelissen and Takken. This is an open-access article distributed under the terms of the Creative Commons Attribution License, which permits use, distribution and reproduction in other forums, provided the original authors and source are credited and subject to any copyright notices concerning any third-party graphics etc. 


\section{APPENDIX}

Table A1 | Primers used in this study.

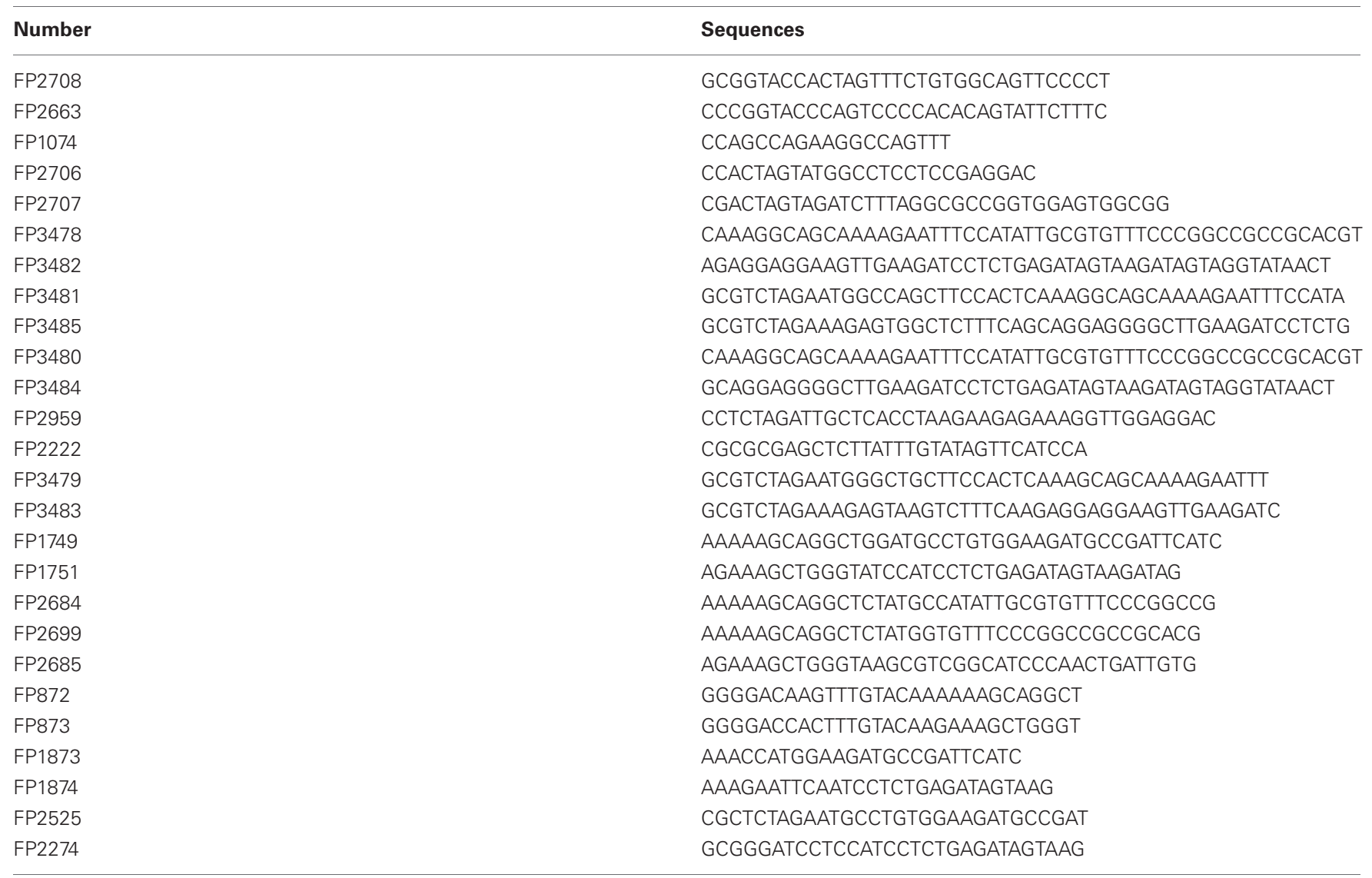

